\title{
Numerical Modelling of Salinity Intrusion: Case Study from Southern Coastal Aquifer in Sri Lanka
}

\author{
S. Priyantha Ranjan
}

\begin{abstract}
A numerical model based on the freshwater-saltwater sharp interface assumption has been developed and it has been applied to estimate the salinity intrusion in the lower part of the Walawe river basin in the southern coastal aquifer, Sri Lanka. Evaluation of the effect of hydro-geological factors on the dynamics of freshwater- saltwater interface has been considered through storage coefficient, porosity and hydraulic conductivity. It concludes that hydraulic conductivity is the main hydrogeological factor affecting the movement of salinity interface. The simulation for groundwater recharge shows that the saltwater intrusion is more sensitive to groundwater recharge than hydro-geological properties. Since storage coefficient and porosity are not much affecting to the change of interface, model was calibrated by adjusting the hydraulic conductivity to match the observed salinity profile in the southern coastal aquifer. The observed long term salinity profile has been compared with the simulation results. It shows that the numerical models can be used to reproduce the salinity profile in the area.
\end{abstract}

Keywords: Salinity intrusion, Groundwater resources, Hydrogeology, Southern coastal aquifer

\section{Introduction}

The use of coastal aquifers as operational reservoirs in water resources systems requires the development of tools that make it possible to predict the behavior of the aquifer under different conditions. Studies on the freshwatersaltwater interface either in steady or transient conditions have become necessary in designing and planning of groundwater systems in coastal areas. The quarititative understanding of the patterns of movement and mixing between freshwater and saltwater, and the factors that influence these processes, are necessary to manage the coastal groundwater resources.

In nature, the freshwater-saltwater interface seldom remains stationary. Large scale recharging into and withdrawals from the aquifer, result in the movement of the interface from one steady position to another. The main objectives of this study are to develop a numerical model to understand the behavior of the freshwater- saltwater interface and to evaluate the effects of different hydro-geological settings and to apply the model to the lower part of the Walawe river basin in the southern coastal aquifer in Sri Lanka.
1.2 Modeling of the dynamics of freshwater saltwater interface

Many models have been developed to represent and to study the problem of saltwater intrusion. They range from relatively simple analytical solutions to complex numerical models. The first concept about freshwater saltwater interface, now widely cited as the Ghyben Herzberg principle, is based on the hydrostatic equilibrium between fresh and saline water. After introducing the Ghyben - Herzberg principle, several analytical and numerical solutions were developed to describe various forms of boundary conditions of cross sectional systems. Recently, studies involving the movement of fresh groundwater and saltwater in coastal aquifer systems have been classically studied using two different approaches [1]. In the first approach, freshwater and saltwater are assumed completely immiscible and a sharp interface exists between these two phases. In the other approach, the freshwater and saltwater are

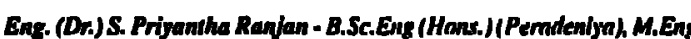
(ATT), D. Eng (Tohntu). AMIESL). Dr Probumhn Ranion is a Lertuner in the Depanment of Civil and Eavinmmeninl Engineering. University of Ruhuna. He was awanted SSPS post dactoral fellowship and presently he is worting as a post doctornd researrher in Thatu Univershy Javen His resenreh imenesss are water resourres engineering and emiluatlon of glabal waming and climate change scenarlas. 
assumed to be in dynamic equilibrium resulting from the flow and dispersion mechanisms within the aquifer. Normally, this method is used in solute transport evaluations.

Density dependent solute transport models are limited to two dimensional vertical cross sections. Three dimensional cases are limited in their application to regional coastal systems by computational constraints [2]. Sharp interface models are useful for vertical cross sections as well as aerial simulations and can represent the bulk freshwater and saltwater flow characteristics of the system. The sharp interface approach, in conjunction with integration of the flow equations over the vertical, can be applied aerially to large physical systems.

The sharp interface models which solve the coupled freshwater and saltwater flow equations have been developed with different numerical techniques $[3,4]$. A finite element method solution with indirect toe tracking technique was presented [5]. Polo and Ramis discussed an unconditionally convergent finite difference approach to solve sharp interface problems [6]. A sharp interface model which solves the coupled freshwater and saltwater flow equations has been developed and it was successfully applied to evaluate multilayered aquifer systems [7].

\section{Mathematical development of sharp interface model}

Sharp interface models couple the freshwater and saltwater flow based on the continuity of flux and pressure. In this approach, together with Dupuit approximation, for each flow domain the equation of continuity may be integrated over vertical direction and come up with following system of differential equations [8].

$$
\begin{gathered}
\frac{\partial}{\partial x}\left[K_{s}\left(h^{\prime}-h^{\prime}\right) \frac{\partial h^{\prime}}{\partial x}\right]+\frac{\partial}{\partial y}\left[K_{\delta}\left(h^{\prime}-h^{\prime}\right) \frac{\partial h^{\prime}}{\partial y}\right]+q_{j} \\
=S_{f} \frac{\partial h^{\prime}}{\partial t}-\theta\left[(1+\delta) \frac{\partial h^{\prime}}{\partial}-\delta \frac{\partial h^{\prime}}{\partial t}\right]+\alpha \theta \frac{\partial h^{\prime}}{\partial t} \\
\frac{\partial}{\partial x}\left[K_{x}\left(h^{\prime}-z^{\circ}\right) \frac{\partial h^{\prime}}{\partial x}\right]+\frac{\partial}{\partial y}\left[K_{s y}\left(h^{\prime}-z^{b}\right) \frac{\partial h^{\prime}}{\partial y}\right]+q_{s} \\
=S_{s} \frac{\partial h^{\prime}}{\partial t}+\theta\left[(1+\delta) \frac{\partial h^{\prime}}{\partial t}-\delta \frac{\partial h^{\prime}}{\partial t}\right]
\end{gathered}
$$

The location of the interface elevation is given by

$h=\frac{\rho_{s}}{\rho_{s}-\rho_{f}} h^{\prime}-\frac{\rho_{f}}{\rho_{s}-\rho_{f}} h^{\prime}$

where $\rho_{f}$ and $\rho_{s}$ are specific weight in fresh and salt water respectively, $h^{\prime}$ and, $h^{*}$ are the piezometric heads of freshwater and saltwater regions, $\rho_{f}$ and $\rho_{s}$ are flow rate in fresh and salt water respectively. $K_{f}$ and, $K_{s}$ represent the hydraulic conductivity in fresh and salt water regions. Storage coefficients in fresh and salt water regions are given by $S_{f}$ and $S_{s}$ respectively. $\theta$ is the porosity of the aquifer media. $\alpha=1$ for unconfined aquifer and $\alpha=0$ for contined aquifer.

\subsection{Numerical scheme}

Except for very simple systems, analytical solutions of those two coupled non linear partial differential equations are rarely possible. Various numerical methods must be employed to obtain approximate solutions. From equations (1) and (2), it is possible to derive a numerical model using implicit finite difference techniques. The continuous system described by above two equations are replaced by a finite set of discrete points in space and time, and the partial derivatives are replaced by terms calculated from the differences in both freshwater and saltwater head values at these points. Spatial discretization is achieved using a block entered finite difference grid which allows for variable grid spacing.

\section{Evaluation of the effect of hydro- geological factors}

To investigate the effect of hydro-geologic factors mainly, specific storage, porosity and hydraulic conductivity on the dynamics of the freshwater-saltwater flow systems, a $2 \mathrm{~km} \times \mathbf{2} \mathbf{k m}$ horizontal strip of an unconfined aquifer has been simulated by changing the hydrogeological properties while observing the system's transient responses. The effect of the specific storage was evaluated by increasing the storage coefficient by orders of magnitude. The change in storage coefficient does not affect the location of the interface. The system responds in almost the same manner for different specific storage values because most of the water to 
fulfill the changes in storage comes from the drainage of the water table rather than an elastic storage. The other factor which illustrates the storage of the aquifer is the porosity. To investigate the effect of porosity on the behavior of the flow system, the porosity was changed from 0.1 to 0.4 in increments of 0.1 . The change in the porosity does not lead to change in the position of the interface. It leads the change in the time period to achieve the steady state of the interface. Fig 1 shows the time taken to achieve the steady state interface at $500 \mathrm{~m}$ away from the coastline. Reduction in porosity accelerates the movement of the interface and it drives the system to a steady state over a shorter time period. Theoretically, it can be explained that the freshwater heads fall to a steady state more rapidly since less water must drain from the pores and the interface change more rapidly.

Another factor affecting the change of the position of freshwater-saltwater interface is hydraulic conductivity. The hydraulic conductivity was changed over the range of $10^{3}$ $\mathrm{m} / \mathrm{s}$ to $10^{-4} \mathrm{~m} / \mathrm{s}$. Those values are in the hydraulic conductivity range for clean sand or basalt aquifers. Fig 2 explains that the changes in hydraulic conductivity have an impact on the steady position of the interface. The change in hydraulic conductivity makes changes in the transmissivity and it affects the head gradients necessary to maintain the freshwater flux. This process showed that the model is very sensitive with respect to changes in hydraulic conductivity than other hydro-geological factors.

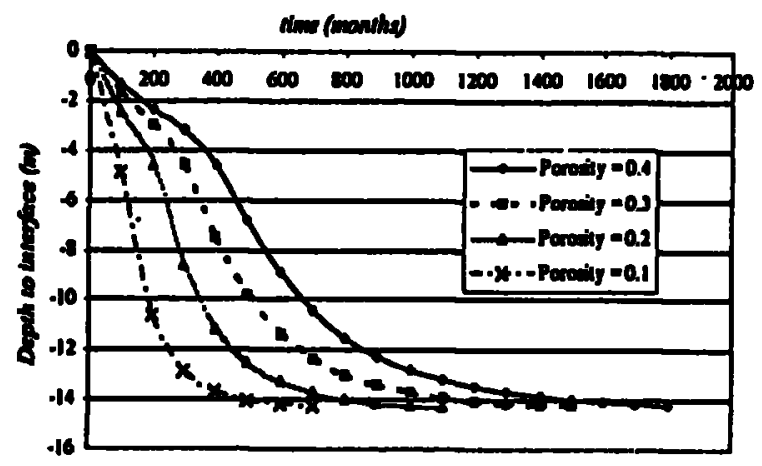

Fig 1. Effect of porosity on the steady state of the interface

\subsection{Simulation of the effect of recharge}

The effect of recharge on the dynamics of the freshwater-saltwater interface can be understood most readily by considering a simple, finite ground water flow system in

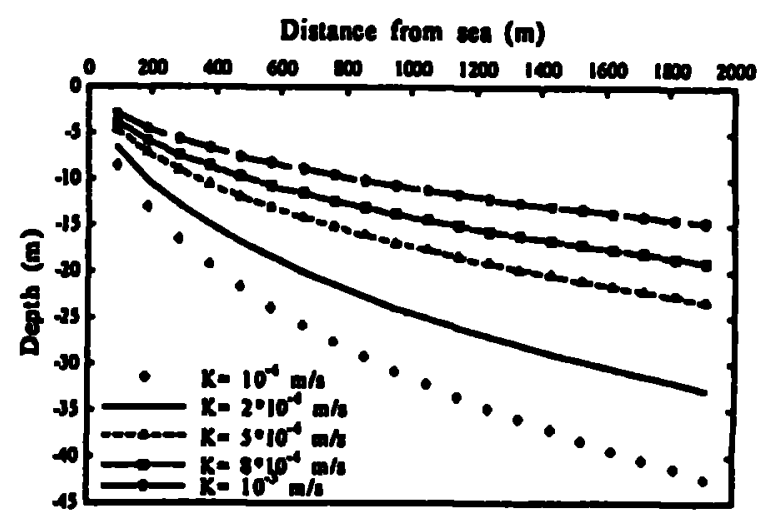

Fig 2. Change in the interface with hydraulic conductivity (K)

which all discharge flows to the ocean. Different annual average groundwater recharge values have been simulated to observe the change of interface with groundwater recharge. Fig. 3 shows the variation of steady interface with groundwater recharge. It shows that higher recharge can reduce saltwater intrusion effectively. The saltwater will intrude farther inland than now occurring unless the amount of additional recharge can push the seawater equilibrium surface seaward.

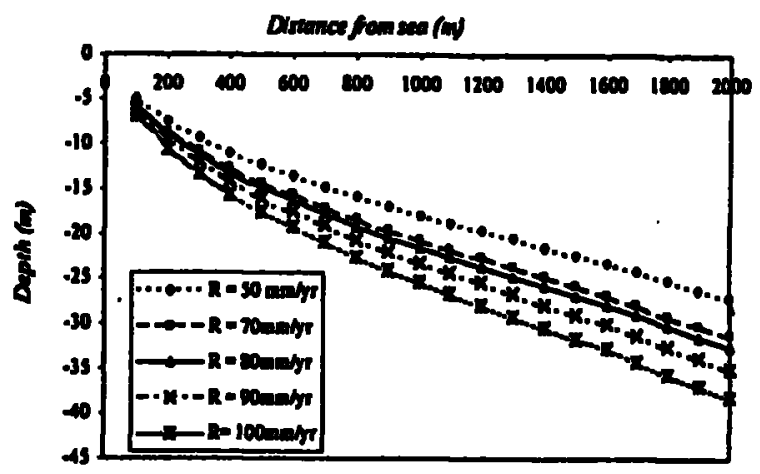

Fig 3. Change in the interface with groundwater recharge

\section{Application to the coastal aquifer in Walawe river basin}

Our main consideration for field data collection was the lower part of the Walawe river basin located in the southern coastal region which is in the southern part of Sri Lanka (Fig 4). The Coastal Plains covering a major part of the southern region has an elevation less than $6 \mathrm{~m}$ above Mean Sea Level (MSL), parallel to the coast [9]. The width of the coastal plains generally ranges from $2 \mathrm{~km}$ to $10 \mathrm{~km}$. Coastal alluvial soils as well as laterites cover the area parallel to the coast. It includes the river sediments and fine to medium green quartzite 
sand, silty sands of the plains and grey to dark grey beach sands [10]. Groundwater within the area is constrained by the unconsolidated alluvial and deltaic sediments, which were deposited by main rivers and their tributaries [11].

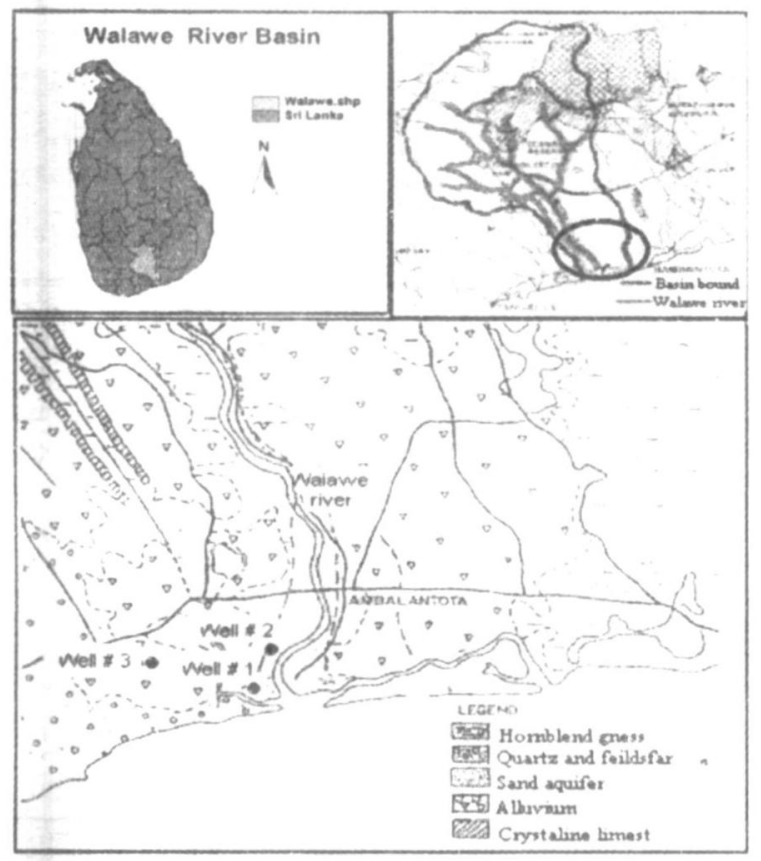

Fig 4. Locations of observation wells in the lower part of Walawe basin in southern coastal aquifer

\subsection{Calibration and verification of the model using field observation}

The usual calibration and verification procedure by the use of analytical solutions is complicated due to the nonlinear nature of saltwater flow. In general, there are no exact solutions for this type of problem for comparison, except a rather limited number of analytical and semi-analytical solutions for specific cases $[12,13]$. Therefore, a verification of results with field data is required to test numerical models. Indeed the availability of such secondary data is not very frequent due to the complexity of measuring and collecting information [14].

Field data observation is carried out in the lower part of the Walawe river basin located in the southern coastal aquifer in Sri Lanka. Several observation wells have been used to measure the change in salinity profile in the area. The observation wells were selected at different distances from the coastline. Since it shows frequent change in salinity intrusion, for calibration and verification of simulated results, observation wells have been selected up to $2 \mathrm{~km}$ away from the coastline. Well \# 1 is around
$400 \mathrm{~m}$ away from the coast. Well \# 2 and well \# 3 are $1 \mathrm{~km}$ and $2 \mathrm{~km}$ landward from the coast, respectively. These wells are located at different levels and at such a distance and depth that in case of salinisation the eventual progression of the saline front can be observed. Salinity was measured using the salinity meter, WQC-24. It detects the salinity in terms of electrical conductivity and the temperature and reproduces the salinity value as the direct measurement of psu. Weekly salinity measurements have been taken during the period of investigation (September 2003 November 2004). Using the vertical salinity profiles of the observation wells, the depth to the freshwater-saltwater interface was estimated. The observation of a sharp interface is practically difficult in the field. Sharp interface studies in the literature show that $50 \%$ salinity contour is the best representation of sharp interface between saltwater and freshwater regions [15-17]. Therefore, we assume the 50\% seawater salinity contour as the equivalent sharp interface assuming that the seawater salinity is $32 p s u$ and the sharp interface ( $50 \%$ seawater salinity profile) at the location of 16 psu salinity profile.

\subsection{Model calibration}

The single-layer approach to modeling aquifers allows all minor variations to be incorporated into a single hydro-stratigraphic unit. In this work the study area is being simulated as a single-layer unconfined aquifer, with a bottom slope defined by the position of the granite bedrock. The simplified model developed, has assumed homogeneous aquifer properties. Because the lower part of the Walawe basin is not under any major stress such as extensive pumping, it was assumed that the aquifer is in the steady condition until the change in groundwater recharge disturbs the system. On the sea side model boundary, a hydrostatic pressure was imposed where pressure is zero at the sea surface. For the calibration of the model for initial steady state condition, the average elevation to the observed freshwater-saltwater interface in the first three months of the observation period (Sep 2003-Dec 2003) has been considered. The average depth to sharp interface has been estimated as $13.5 \mathrm{~m}$ at well \#1. The depth to the sharp interface at the observation well \#2 was $21.5 \mathrm{~m}$ and at the observation well \#3 was at $34 \mathrm{~m}$ depth. 
As mentioned in the parameter estimation, the main hydro-geological factors affecting the dynamics of freshwater - saltwater interface are the hydraulic conductivity and the recharge of the aquifer. The average annual groundwater recharge in the Walawe river basin has been estimated as $80 \mathrm{~mm} /$ year [18]. This value has been used here as a realistic value to represent the groundwater recharge in Walawe basin and the simulation runs were conducted with recharge value of $80 \mathrm{~mm} /$ year to generate the steady state condition.

For the calibration process, a wide range of values for each parameter has to be used to estimate the most suitable value. Since the hydraulic conductivity is the main hydrogeological factor affecting the movement of salinity interface, it has been planed to calibrate the model by adjusting hydraulic conductivity values to match the steady interface location with the field observed value at observation wells. The hydraulic conductivity varies across the area and the estimated data of hydraulic conductivity is varied in a large range and diversity The hydraulic conductivity of the coastal plain of the Walawe river basin has been estimated using the available pumping test results and bore hole data $[19,20]$. Aquifer materials and their deposition was observed from bore-hole data and relevant hydraulic conductivities have been assigned [21]. Hydraulic conductivity is low at the upper part of the aquifer and it gives a large value at the lower part. The coastal plain consists of river sediments and fine to medium green quartzite sand, silty sands of the plains and grey to dark grey beach sands and the hydraulic conductivity is estimated to be varied between $10^{-4} \mathrm{~m} / \mathrm{s}$ to $10^{-}$ ${ }^{3} \mathrm{~m} / \mathrm{s}$ [21].

Considering the varying properties of the aquifer, several model runs were carried out to find the most reliable location for the steady state salinity intrusion profile. The best fitting profile with the field observation data is shown in Fig 5

\subsection{Verification of the model}

Model verification is the process of demonstrating that the calibrated model is an adequate representation of the physical system. Owing to uncertainties in the parameter values used in the calibration, the calibrated model

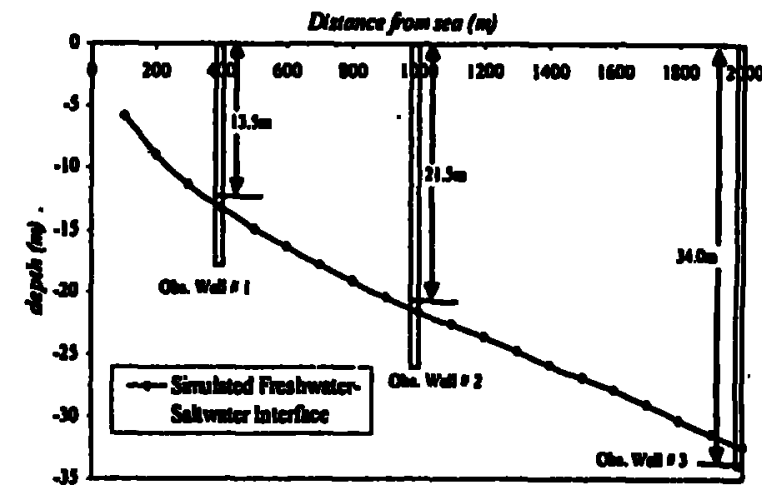

Fig 5. The best fitting profile of the field observation with calibration of model results

may not be accurately representing the field conditions. Therefore the calibrated model has been used to verify the model for short term changes in freshwater-saltwater interface.

In this study, the groundwater recharge is the main influencing factor for the dynamics of the saltwater-freshwater interface. Recharge of the groundwater system is by a number of different processes. Here, the groundwater recharge has been estimated using water balance approach. Meteorological data of the Walawe river basin has been obtained from the International Water Management Institute (IWMI) database of Walawe benchmark basin. This data base has been used to estimate daily groundwater recharge and corresponding monthly average groundwater recharge. Estimated groundwater recharge shows that groundwater resources in Walawe basin recharges in two seasons per year. The two rainy periods are south-west monsoon season in October - December and north-east monsoon season in April-June. In other months the groundwater recharge is zero.

The outputs from steady state results were used as an initial condition to simulate realistic shorttime effects of changes in groundwater recharge on the system. During the model verification period, the model coefficients obtained from the calibration period were kept as constants, and the model was used to predict the salinity based on the input of the change of groundwater recharge. Model sensitivity was examined for different short term changes in groundwater recharge. The data for the period of January 2004 to November 2004 was used for verification of the calibrated model.

A series of monthly interface profiles for monthly recharge rates were obtained using a 
calibrated model. Continuous short term observations (weekly) are available for well-1 and well-2. These observations have been used to estimate the average monthly salinity profile and were used to verify the model. Fig 6 shows the weekly variation of the sharp freshwater saltwater interface and the monthly averaged interface in observation well 1 and well 2.

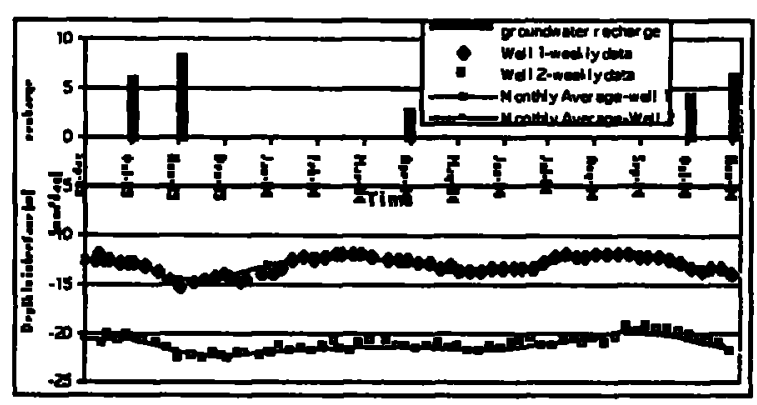

Fig 6 Weekly variation of the sharp freshwater saltwater interface

Comparison of the simulated monthly freshwater-saltwater interface profiles and the monthly averaged observed salinity profiles in Walawe river basin are shown in Fig. 7. The results show that the comparisons between the observed and modeled salinity have been quite well predicted. Observations are well matched with model output, especially where there is a lowering of the interface can be observed in October - December and March- June due to positive groundwater recharge. The model also well reproduces these changes.

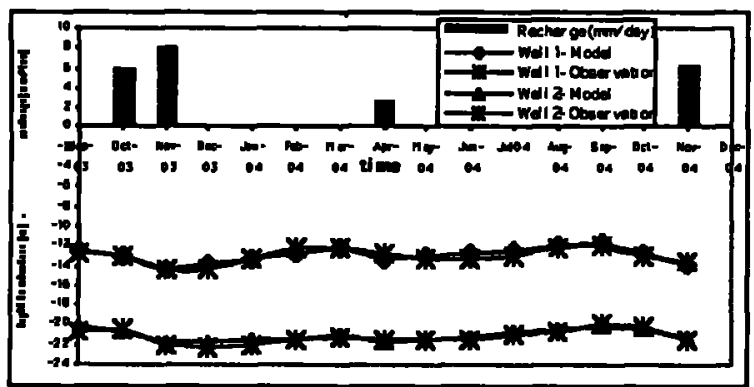

Fig. 7 Comparison between obseroations and model output

The correlation between simulated and observed interface have been shown in Fig 8 and Fig 9. The correlation coefficients between model predictions and field observations for well \# 1 and well \#2 are present as 0.86 to 0.77 . This correlation shows a good agreement and can be increased owing to uncertainties in the hydraulic conductivity of the aquifer and it shows that the comparison of the observed data with modeling results has been found to be in reasonable agreement.

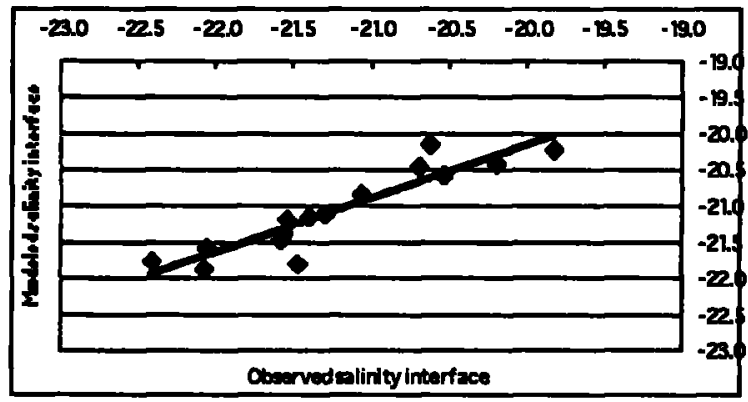

Fig. 8 Comparison of observed and modeled interface at roell $\# 1$

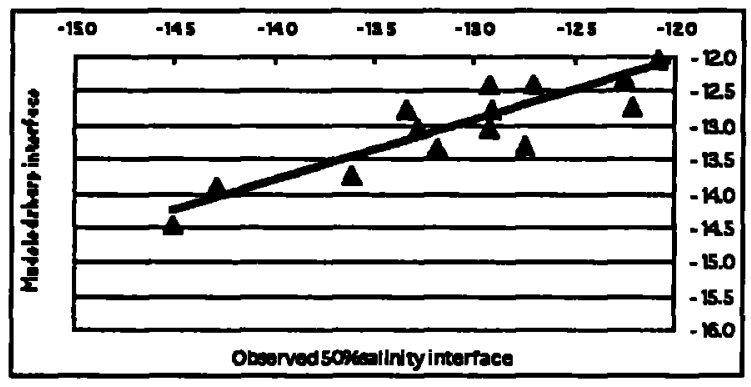

Fig. 9 Comparison of observed and modeled interface at well \# 2

These kind of simulations show that the numerical models can be used to reproduce the salinity profile in the complex hydro-geological settings. It further concludes that any groundwater development activity in the southern coastal aquifer needs to be carefully planned with remedial measures in order to prevent the further intrusion of seawater.

\section{Conclusions}

The developed sharp interface model has been applied to the lower part of the Walawe river basin in the southern coastal aquifer, Sri Lanka. Evaluation of the effect of hydro-geological factors on the dynamics of freshwater- saltwater interface concluded that hydraulic conductivity is the main hydro-geological factor affecting the movement of salinity interface. The simulation for groundwater recharge shows that the 
saltwater intrusion is more sensitive to groundwater recharge than hydro-geological properties. The numerical model was calibrated by adjusting the hydraulic conductivity to match the observed salinity profile in the southern coastal aquifer. The observed long term salinity profile has been compared with the simulation results to verify the model. It shows that the numerical models can be used to reproduce the salinity profile in the southern coastal aquifer.

\section{Acknowledgement}

The author would like to acknowledge the support from Dr. So Kazama and Prof. Masaki Sawamoto of Tohoku University, Japan. The author would also like to express his thanks to Mr. Dinesh for conducting the field observations

\section{References}

1. Reilly, T.E., Goodman, A. S., Quantitative analysis of fresh-salt water relationship in groundwater systems- A historical perspective, J. of Hydrology , 80, pp.125-149, 1985

2. Essaid, H.I., A Multilayered sharp interface Model of coupled freshwater and saltwater flow in coastal systems: Model development and application, Water Resources Research, 26(7), Pp.1431 -1455, 1990

3. Shamir, U., Dagan, G., Motion of Saltwater interface in a coastal aquifers: A numerical solution, Water Resources Research, Vol. 7 No.3, (1971), pp644-657.

4. Vappicha, V.N., Nagaraja, S.H., An approximate solution for the transient interface in a coastal aquifer, Journal of Hydrology, Vol.31, (1976), pp161-173.

5. Wilson, J.L., Sa Da Costa, A., Finite element Simulation of Salt-fresh water interface with indirect toe tracking, Water Resources Research, Vol.18, No.4, (1982), pp1069-1081

6. Polo, J.F., Ramis, FJ.R., Simulation of Salt-fresh water interface model, Water Resources Research, Vol. 19, No.1, (1983), pp61-68.

7. Essaid, H.I., A Multilayered sharp interface Model of coupled freshwater and saltwater flow in coastal systems: Model development and application, Water Resources Research, 26, pp.1431-1455. 1990

8. Bear, J., Cheng, A.H.D., Sorek, S., Ouazar, D., and Herrera, I., Seacuater Intrusion in Coastal Aquifers-
Concepts, Methods and Practices, Kluwer Academic Publishers, 1999.

9. Engineering Consultants Ltd., 1995, Water Resources Inventory Study for Southern Area of Sri Lanka -Volume 1, Main Report, 1995.

10. Statkraft Groner, Third Water Supply and Sanitation Project, Water Resources Management- Annex D, Groundwater, Walawe Ganga Basin., pp83, 2000.

11. Kulatunga, N., Hydrology of a Metamorphic Terrain: A Case Study from Hambantota, Sri Lanka., Journal of the Geological Society of Sri Lanka, Vol. 1, 1998.

12. Glover R.E., 1959. The pattern of freshwater in a coastal aquifer., Journal of Geophysical Research, V.64, No.4, 1959.

13. Bear, J., Hydraulics of Groundwater, McGraw-Hill, New York, 1979.

14. Melloul, A.J., and Goldenberg, L.C., Monitoring of seawater intrusion in coastal aquifer: basic and local concerns, Journal of Environmental Managemen, 51, pp. 73-86, 1997.

15. Mahesha, A., and Nagaraja S. H., Effect of natural recharge on sea water intrusion in coastal aquifers, Journal of Hydrology, 174(3-4), Pp 211-220, 1996

16. Scot, K.I., Stephen, B.G., 1998, Estimation of the depth to the fresh-water/salt-water interface from vertical head gradients in wells in coastal and island aquifers, Hydrogeology Journal, 6, pp 365-373.

17. Masciopinto, C., Simulation of coastal groundwater remediation: the case of Nardo fractured aquifer in Southern Italy Environmental Modelling \& Software, 21/1, pp 85-97, 2006.

18. Ranjan, S.P., Kazama, S., Sawamoto, M., Effects of climate and land use changes on groundwater resources in coastal aquifers, Jourual of Environmental Management, 80(1) pp. 25-35, 2006

19. Jayaweera, $U$, unpublished Report on Alluvial Aquifer Studies at Lower Part of the Walawe River Basin, Water Resources Board, Sri Lanka, 2001

20. JICA, The Study on comprehensive groundwater resources development for Hambantotaand Monaragala districts in Sri Lanka, Interim report for Water Resources Board; Ministry of Irrigation and Water Resources Management. Sri Lanka, 2003.

21. Freeze, R.A., Cherry, J.A., 1979, Groundwater, Prentice Hall International, London, (Chapter 2). 